\title{
Endodontic treatment of rare anatomical complexity, two canals in maxillary lateral incisor: A case report
}

\author{
Shalini Singh ${ }^{1, *}$, Eliezer Rapsang $^{2}$, Nitin Mirdha ${ }^{3}$, Yesh Sharma ${ }^{4}$, Rahul VC Tiwari ${ }^{5}$ \\ ${ }^{1,2,4}$ Postgraduate Student, ${ }^{3}$ Associate Professor, ${ }^{5}$ Fellow, ${ }^{1,2,3,4}$ Dept. of Conservative Dentistry and Endodontics, ${ }^{5}$ Dept. of Oral \\ and Maxillofacial Dentistry, ${ }^{1,3}$ Vyas Dental College and Hospital, Jodhpur, Rajasthan, ${ }^{1,4}$ Maharaja Ganga Singh Dental College, \\ Siriganganagar, Rajasthan, ${ }^{5}$ Jubilee Mission Medical College Hospital and Research Institute, Thissur, Kerala, India
}

*Corresponding Author:

Email: drshalinisingh27@gmail.com

\begin{abstract}
Maxillary lateral incisors classically has configuration of one root with one canal. However, variation in anatomy and morphology is not an exception. Radiographs from different angulations specially mesial and distal are critical in such cases of atypical root canal anatomy, although more precision can be expected with operating microscope and cone-beam computerized tomography (CBCT). Meticulous knowledge and careful diagnosis of canal configurations, developmental anomalies and careful pretreatment assessment of radiographs is essential. This case report enlightens the need for consideration during endodontic management of maxillary lateral incisors.
\end{abstract}

Keywords: Maxillary lateral incisor, Two canals, Endodontic management.

\section{Introduction}

Endodontic literature usually describes maxillary lateral incisors as single root and canal configuration. Several studies have cited the presence of variant configuration anatomically and morphologically in relation with roots and root canals. ${ }^{1,2}$ Maxillary lateral incisor is associated with developmental anomaly which when evaluated clinically or radiographically can be categorized as follows: germination, fusion, concrescence, or dens invaginatus, since they are frequently positioned at high embryological risk zone. ${ }^{3}$ Comprehensive acquaintance of the variations in roots and canal morphology and anatomy is considered as the vital part in endodontics, as any missed canal or extra roots lead to endodontic failure. ${ }^{4}$

\section{Case Report}

A 22 year female patient reported to Department of Endodontics with the chief complaint of pain in maxillary anterior region since 3 months. The patient had historical backdrop of injury five months ago. On clinical assessment revealed discolored crown with lateral incisor. On vitality testing with electronic pulp tester, both central and lateral incisors showed no response indicating that the teeth are non-vital necessitating endodontic therapy. On radiographic assessment two separate canals were clearly identifiable in relation to left maxillary lateral incisor (Fig. 1(a)).

As the tooth was non-vital endodontic access cavity preparation was done without anesthesia, while maintaining the isolation using rubber dam from maxillary right canine to left canine. Along the dentinal map, the second canal was identified without difficulty by extending the access cavity palatally. Working lengths were confirmed with the use of an apex locator (Root ZX, Morita, Japan) and size 15K stainless steel files. Copious irrigation was done using 30G side vented needle $1 \mathrm{~mm}$ short of working length with $5 \%$ sodium hypochlorite and 17\% EDTA alternatively, recapitulations was performed and the chemomechanical preparation was performed up to a size $30 \mathrm{~K}$ stainless steel files using the step-back technique. Master cone selection radiograph was taken by placing gutta-percha (30/0.02) in both the canals (Fig. 1(b)). Cold lateral compaction technique was selected for obturation using gutta-percha and Sealapex (as a sealer). Filtek Z350 XT composite resin (3M ESPE, St. Paul, MN, USA) was used for post obturation restoration and a postoperative radiograph was taken (Fig. 1(c)).

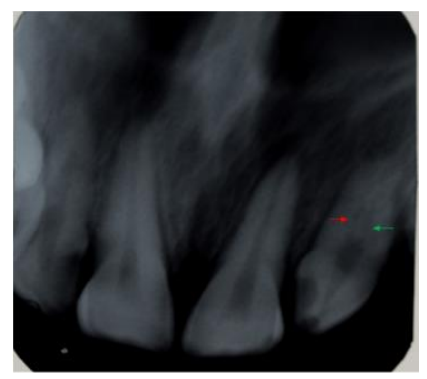

Fig. 1(a): Preoperative radiograph

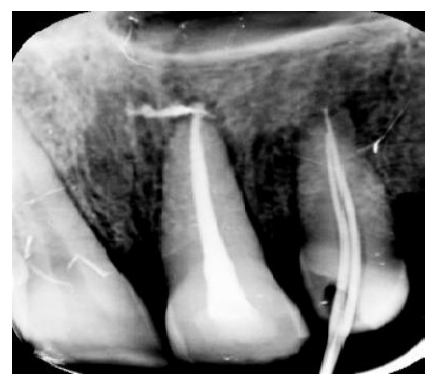

Fig. 1(b): Mastercone selection radiograph 


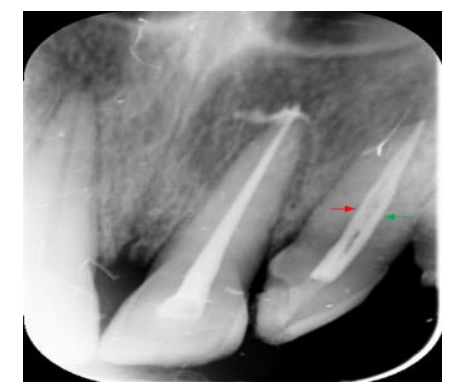

Fig. 1(c): Post-obturation periapical radiograph

\section{Discussion}

Teeth with atypical root and root canal configurations are challenge to the most clinicians, and in many situations, the tooth has been advised for extraction due to failure to negotiate presence of extra roots and root. ${ }^{5}$ More than one canal in maxillary central and lateral incisors is a very rare finding. In fact, according to the study on morphology and anatomy of maxillary anterior teeth done by Vertucci in 1984, $100 \%$ of these teeth showed single canal. In contrast to Vertucci's study, DeDeus in 1992 conducted a survey and reported that approximately $3 \%$ of maxillary lateral incisors had two canals. Citation of multiple canals in these teeth is limited to case reports of developmental anomalies known as fusion, gemination or dens invaginatus. ${ }^{6,7}$

The likelihood of numerous canals in the maxillary lateral incisor comes to fruition due to its high embryological risk position. ${ }^{5}$ All through the fourth and sixth weeks of advancement of human developmental life, the upper arch, from which the lateral incisors originate, forms by the unification of the paired maxillary processes (MP) and medial nasal processes (MNP). As the MNP fuse with each other, they form the premaxilla, including the medial portion of the upper lip (philtrum) and the primary palate. ${ }^{8}$ The exact inception of the maxillary lateral incisor relative to the MNP/MP fusion vicinity and the location of the premaxillary/maxillary suture in the human is an open query. The MNP/MP fusion vicinity could be medial to the lateral incisor or at the medial or middle one-third of the lateral incisor. The premaxillary/maxillary suture might be between the lateral incisor and canine or at the middle third of the canine. ${ }^{9}$ For these reasons, maxillary lateral incisors may show various root canal morphology.

Considering the variations in configurations anatomically and morphologically in these teeth, the clinician must be careful about not to miss the additional roots and canals, especially when a patient reports with persistent pain or sensitivity to hot and cold after root canal treatment. ${ }^{10}$

\section{Conclusion}

The clinical implication of the present reported case of maxillary lateral incisors is that there may have two or more canals present. Understanding of developmental judicious use of high-end diagnostic aids such as radiographs with varying angulations, CBCT, and an operating microscope should also be used when needed for successful endodontic therapy in complex cases. The clinician is ought to be constantly conscientious to identify anatomic anomalies. The significance of vigilant preoperative evaluation cannot be over emphasized.

\section{References}

1. Pereira AJ, Fidel RA, Fidel SR. Maxillary lateral incisor with two root canals: fusion, germination or dens invaginatus? Braz Dent J 2000;11:141-6.

2. Walvekar SV, Behbehani JM. Three root canals and dens formation in a maxillary lateral incisor: a case report. $\mathbf{J}$ Endod 1997;23:185-6.

3. Lim YJ, Nam SH, Jung SH, Shin DR, Shin SJ, Min KS. Endodontic management of a maxillary lateral incisor with dens invaginatus and external root irregularity using cone-beam computed tomography. Restor Dent Endod 2012;37:50-3.

4. Mohan AG, Rajesh EA, George L, Sujathan, Josy SA. Maxillary lateral incisors with two canals and two separate curved roots. Contemp Clin Dent 2012;3:51921.

5. Estrela C, Lopes HP, Pecora JD. Radicular grooves in maxillary lateral incisor: case report. Braz Dent J 1995;6:143-6.

6. Vertucci F. Root canal anatomy of the human permanent teeth. Oral Surg 1984;58:589-99.

7. DeDeus QD: Endodontia. 1999; 5th ed. Medsi, Rio de Janeiro.

8. Wei X, Senders C, Owiti GO, Liu X, Wei ZN, DillardTelm L, McClure HM, Hendrickx AG. The original and development of the upper lateral incisor and premaxilla in normal and cleft lip/palate monkeys induced with cyclophosphamide. Cleft Palate Craniofac J 2000;37:571-83.

9. Ooe T. On the early development of human dental lamina. Okajimas Folia Anat Jpn 1957;30:198-210.

10. Patel S, Dawood A, Ford TP, Whaites E. The potential applications of cone beam computed tomography in the management of endodontic problems. Int Endod J 2007;40:818-30. 